\title{
The effect of cognitive rehabilitation for post-stroke depression in long-term care health facilities: A randomized controlled trial
}

\author{
Harumi Sakamoto ${ }^{1,2}$, Naoki Maki ${ }^{1,3}$, Atsuhiro Utsugi ${ }^{4}$, Yu Takata ${ }^{2}$, Tomohiro Kubota ${ }^{2}$, Masayoshi Ishida ${ }^{2}$, Shigemi Nakamura ${ }^{2}$, Shinichiro \\ Sasahara ${ }^{5}$, Ichiyo Matsuzaki ${ }^{5}$ and Hisako Yanagi** \\ ${ }^{1}$ Graduate School of Comprehensive Human Sciences, Clinical Sciences, Doctoral Program, University of Tsukuba, Japan \\ ${ }^{2}$ AHR Medical and Welfare College School, Japan \\ ${ }^{3}$ Department of Thoracic Surgery, Faculty of Medicine, University of Tsukuba, Japan \\ ${ }^{4}$ National Public Officers Mutual Aid Association Federation Suifu Hospital, Japan \\ ${ }^{5}$ Occupational and Aerospace Psychiatry Group Graduate School of Comprehensive Human Sciences, University of Tsukuba, Japan \\ ${ }^{6}$ Department of Medical Science and Welfare, Faculty of Medicine, University of Tsukuba, Japan
}

\begin{abstract}
Objective: The purpose of this study is to examine the effects of the cognitive rehabilitation on the depressive symptoms, cognitive function, activities of daily living (ADL), quality of life (QOL), and customer satisfaction in Post-Stroke Depression (PSD) patients.

Design: Randomized controlled trial

Setting: Long-term care health facilities in Ibaraki Prefecture, Japan.

Subjects: Total of 30 participants with either cognitive rehabilitation (intervention group, $\mathrm{n}=15$ ) or additional low-intensity exercise therapy (control group, $\mathrm{n}=15$ ) completed the randomized controlled trial

Intervention: The participants were randomly divided into 2 groups and given 36 sessions of low-intensity exercise therapy, ( 3 sessions a week for 12 weeks) with either cognitive rehabilitation (intervention) or additional low-intensity exercise therapy (control).

Main Measures: Measurements were performed before and after the 36 rehabilitation sessions. Primary outcome measures were severity scores evaluations of depression (the Geriatric Depression Scale [GDS], Zung Self Depression Scale [SDS], Japan Stroke Scale - Depression Scale [JSS-D], Japan Stroke Scale Emotional Disturbance Scale [JSS-E]). Secondary outcome measures included Frontal Assessment Battery (FAB), ADL, QOL and Customer Satisfaction.

Results: Participants who received cognitive rehabilitation showed significantly more improvement in the GDS (95\% confidence interval [CI], $-0.67-5.47 ; \mathrm{P}=.02)$, SDS (95\% CI, 3.68-18.32; P = .01), JSS-D (95\% CI, 0.92-3.11; P = .00), and JSS-E (95\% CI, -.59-4.64; P = .04) than those in the control group.

Conclusions: To the best of our knowledge, this is the first randomized trial to show the efficacy of cognitive rehabilitation to improve the depressive symptoms and cognitive function for PSD patients.
\end{abstract}

\section{Introduction}

Stroke survivors often encounter severe cognitive and emotional consequences [1]. Post-stroke depressive symptoms occur frequently in the chronic phase after stroke [2-6]. Approximately 15 to $60 \%$ of stroke survivors are likely to experience post-stroke depression (PSD). PSD is one of the most important sequela of stroke and adversely affects for cognitive function, ADL, and QOL [7-9]. Patients with PSD were reported to have more functional disability [10], poorer rehabilitation outcomes [11], and increased morbidity and mortality in the first year after stroke onset [12]. Furthermore, in a previous study, we found that patients who were depressed after stroke reported low levels of facility service satisfaction and rehabilitation customer satisfaction [13].

Physioanatomic factors that have been of great interest and of some controversy are the relationships between stroke neuroanatomical localization, overall stroke burden, stroke subtype, and the formation and severity of PSD $[14,15]$. Two studies led by Robinson reported that acute stroke patients with left frontal or left basal ganglia lesions had a significantly higher frequency of major or minor depression than patients with other lesion locations $[16,17]$. Taken together, these findings indicate that frontal lobe function is significantly involved in PSD.

${ }^{*}$ Correspondence to: Hisako Yanagi, Department of Medical Science and Welfare, Faculty of Medicine, University of Tsukuba, 1-1-1 Tennodai, Tsukuba, Ibaraki 305-8577, Japan, Tel: 029-853-3496; E-mail: hyanagi@md.tsukuba.ac.jp

Key words: stroke, depression, post-stroke depression, cognitive rehabilitation, QOL, customer satisfaction

Received: June 08, 2018; Accepted: June 13, 2018; Published: June 20, 2018 
Studies on the treatment of PSD have generally focused on pharmacological interventions [18,19], while non-pharmacological interventions for PSD have hardly been investigated. Pharmacotherapy has been shown to relieve PSD, however, its usefulness is limited because of frequent adverse effects [20]. There are numerous treatments for depression and anxiety with varying degrees of effectiveness. Physical activity has been shown to be associated with a decrease in depression and anxiety symptoms. Physical activity has been consistently shown to be associated with improved physical health, life satisfaction, cognitive functioning, and psychological wellbeing [21]. Several reports suggest that exercise is a promising, low-risk intervention that might be helpful in prevention and treatment of depression in elderly residents of care homes [22,23].

Cognitive rehabilitation is a rehabilitation program that involves repeated practice of standardized tasks that target particular cognitive functions, what might be referred to as 'cognitive stimulation [24].' Cognitive rehabilitation stimulates different brain areas that are activated by each task to be performed. Hwi-Young Cho and colleagues [25] reported that computer cognitive training led to activation of the frontal lobe and improvement of memory and attention of stroke patients. Given the association between PSD and frontal lobe function, it is possible that activation of the frontal lobe function through cognitive rehabilitation could lead to improvement of PSD, which, in turn, is likely to lead to an improvement in ADL and QOL patients with PSD.

To test this hypothesis, we previously conducted a pilot-study of cognitive rehabilitation for patients with PSD, which included preand post-evaluation, but not a control group. Results of this pilotstudy indicated that cognitive rehabilitation has favorable effects on depression, frontal lobe function, and QOL [26]. However, recently, the favorable effects of exercise therapy on depression have been reported [23]. Therefore, we considered that it is necessary to compare cognitive rehabilitation and low-intensity exercise therapy, as typically used in rehabilitation programs, to compare their respective therapeutic effects on PSD. The purpose of the current study was to conduct a randomized controlled trial (RCT) to examine the effects of cognitive rehabilitation (intervention group) and low-intensity exercise therapy (control group) on depression status, ADL, and QOL in patients with PSD. Furthermore, we examined the effects of cognitive rehabilitation on customer satisfaction with long-term care facility services and rehabilitation programs for PSD patients.

\section{Methods}

\section{Participants}

Participants in this study were recruited between March 2015 and July 2016. They were residents of 5 long-term care health facilities (LTCHFs) in Ibaraki prefecture, Japan. The inclusion criteria were as follows: (1) cerebral infarction or history of cerebrovascular disorders such as cerebral hemorrhage; (2) mood disorders with 2 or more symptoms according to the Diagnostic and Statistical Manual of Mental Disorders fourth edition (DSM-IV) [27] ; and (3) depression, according to the Geriatric Depression Scale (GDS) [28] (more than 5 points), the Japan Stroke Scale - Depression Scale (JSS-D) [29] ( $\leq 2.4$ points).

Exclusion criteria were as follows: (1) taking antidepressants; (2) diagnosis of dementia according to the revised Hasegawa dementia rating scale (HDS-R) [30] (10 points or less) or Independence degree of daily living for the demented elderly (rank IV-M); and (3) participants with higher degrees of brain dysfunction (such as aphasia).
Sample size was calculated using $G^{\star}$ Power. 3.1.9.2 [31]. The calculations revealed that 14 participants in both groups was the minimum sample size required [32]. Figure 1 shows a flow chart of patients' participation in this study. A total of 40 patients were assessed for eligibility. Of those 40 patients, 8 did not consent to the study and the remaining 32 patients were randomized. Of the 16 patients allocated to the intervention group, 1 could not continue the rehabilitation owing to being discharged before completing all 12 sessions. Likewise, 1 of the 16 patients allocated to the control group could not continue rehabilitation owing to being discharged before completion of the sessions. We could not obtain the postintervention outcomes for these 2 patients who withdrew. Finally, a total of 30 patients completed the cognitive rehabilitation program (intervention group, $\mathrm{n}=15$ ) or lowintensity exercise therapy program (control group, $n=15$ ). There were no adverse events in this study.

\section{Study design}

This study was designed as an RCT, with an intervention group and control group. A computer-generated sequence was used to randomize the participants into the control and intervention groups. All participants underwent 36 20-minute low-intensity exercise therapy sessions ( 3 sessions per week for 12 weeks) and an additional 36 20-minute rehabilitation sessions ( 3 sessions per week for 12 weeks) with either cognitive rehabilitation (intervention group) or further lowintensity exercise therapy (control group). Interventions were carried out by skilled and experienced physical therapists or occupational therapists. Baseline measures of each participant's demographics and characteristics were assessed prior to the interventions. Outcome measures were evaluated at 2 points: prior to training (pre-training evaluation), and after the 36 sessions (post-training evaluation).

\section{Cognitive rehabilitation program (intervention group)}

The intervention program consisted of: the Stroop Color-Word Test, Kana Pick-out Test, Digit Span, and the Serial Sevens Test.

\section{Stroop Color-Word Test}

The Stroop Color and Word Test (SCWT), useful in both clinical and experimental contexts, is a neuropsychological test that uses combinations of colors and words to assess ability to inhibit cognitive interference [33]. In this test, the participant says aloud the color of 4 different colored circles. Next the participant reads aloud the names of colors printed in the same colors (for example the word "red" printed in red ink). Finally, the participant reads about the names of colors printed in different colored inks (for example the word "red" printed in blue ink).

\section{Kana Pick-out Test}

The Kana Pick-out Test (KPT), so called because it involves participants "picking out" Japanese Kana symbols from a text, is a useful tool for assessing frontal lobe function. It is often used in Japan for identifying mild dementia [34]. The test involves the dual task of reading a text while (1) identifying as many kana vowel symbols as possible within 2 minutes and (2) understanding the meaning of the text, which is evaluated by answering 10 questions about its contents [34].

\section{Digit Span Test}

The digit span test is a memory test, which assesses a participant's ability to hold a sequence of numbers in their memory. Digit sequences are presented beginning with a length of 2 digits. 


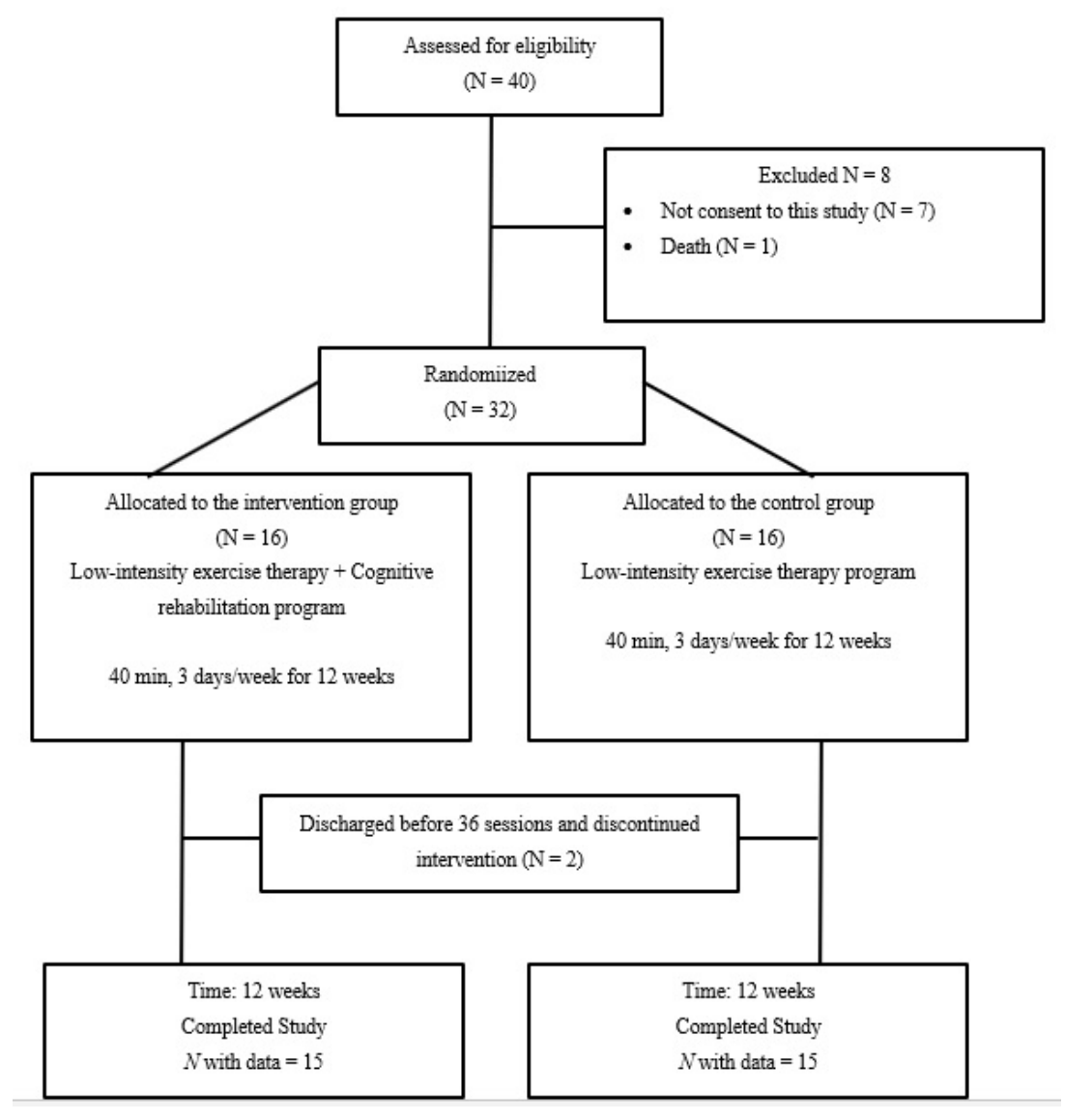

Figure 1. Flow of participant participation

\section{Serial Sevens Test}

The Serial Sevens Test is used in clinical settings to test mental function, perhaps after head trauma or dementia screening. The test involves the participants subtracting 7 from the given number (usually 100 ), and continuing to subtract 7 from successive answers, until told to stop.

\section{Low-intensity exercise therapy program (control group)}

The low-intensity exercise therapy program consisted of the following: (1) range of motion exercise and (2) low-intensity aerobic exercise in the supine position aimed at level 13 of the Borg scale (slightly tight).

\section{Assessment}

All assessment was done by physical therapists or occupational therapist trained to perform standardized assessment procedures. For primary outcome measures, GDS, the Zung Self Depression Scale (SDS) [35], JSS-D, Japan Stroke Scale - Emotional Disturbance Scale (JSS-E) [36] were used to evaluate depression. Secondary outcome measures were HDS-R, Mini-Mental State Examination (MMSE) [37], Frontal Assessment Battery (FAB) [38], Trail Making Test (TMT part A and B) [39], Barthel Index (BI) [40], independence degree of daily living for the demented elderly, Rehabilitation Customer Satisfaction (the Customer Satisfaction Scale based on Need Satisfaction [CSSNS]) [41], Facility Service Satisfaction, and SF-8 [42]. The Facility Service Satisfaction instrument uses a 50-point scale ( 0 points [dissatisfaction] to 49 points [satisfaction]) and is composed of 23 items across 6 categories: impression of life in general, care of health, service contents, leisure activity, life task, and comprehensive evaluation. The Customer Satisfaction Scale based on Need Satisfaction (CSSNS) uses a 75 -point scale ( 0 points [dissatisfaction] to 75 points [satisfaction]) and is composed of 15 items across 5 categories: competence, autonomy, relatedness to participant, relatedness to service provider, and physiological need. The evaluators were blinded to intervention allocation. Participants and therapists were not blinded to intervention allocation.

\section{Statistical analysis}

SPSS version 21.0 was used for all statistical analyses. Fisher exact test and Mann-Whitney U test were used to compare the characteristics between intervention group and control group (Table 1). Comparisons were made using Wilcoxon signed-rank test and Mann-Whitney $\mathrm{U}$ test for intervention group and control group (BI, HDS-R, MMSE, FAB, GDS, SDS, JSS-D, JSS-E, Facility Service Satisfaction, CSSNS, SF8) (Table 2). Adjustment was made using the Bonferroni method for multiple testing (Tables 2 and 3). Sample size was calculated using the effect sizes. The sample size of this study has sufficient detection power. Statistical significance was set at $P<.05$.

\section{Ethical considerations}

This study was conducted with the approval of the ethics committee of the University of Tsukuba (approval number: 943). All participants provided written informed consent after receiving a full written description of the study. The trial was prospectively registered through Clinical Trial Registry (University hospital Medical Information Network (UMIN) number: 000029117 https:/upload.umin.ac.jp/cgiopen-bin/ctr/ctr_view.cgi?recptno=R000033266). 
Table 1. Demographic characteristics of subjects who completed study

\begin{tabular}{|c|c|c|c|c|c|c|}
\hline \multirow{2}{*}{\begin{tabular}{|l} 
Characteristics \\
Sex \\
\end{tabular}} & \multirow[b]{2}{*}{ Female(\%) } & \multicolumn{2}{|c|}{ Intervention group $(\mathrm{N}=15)$} & \multicolumn{2}{|c|}{ Control group $(\mathrm{N}=15)$} & \multirow{2}{*}{$\begin{array}{c}\text { P value } \\
.25\end{array}$} \\
\hline & & 12 & $(80.0 \%)$ & 8 & $(53.3 \%)$ & \\
\hline $\mathrm{Age}^{\mathrm{b}}$ & & $82.6 \pm 9.2$ & (56 to 93 ) & $77.9 \pm 9.8$ & (59 to 95$)$ & .10 \\
\hline Residents period (Day) ${ }^{\mathrm{b}}$ & & $721.9 \pm 810.0$ & (62 to 2687 ) & $844.0 \pm 995.5$ & (333 to 3938 ) & .36 \\
\hline Certified as requiring care (levels) $^{\mathrm{b}}$ & & $3.1 \pm 0.9$ & ( 2 to 5$)$ & $3.0 \pm 1.5$ & (2 to 5$)$ & .79 \\
\hline \multirow{4}{*}{$\begin{array}{l}\text { Independence degree of daily living } \\
\text { for the demented elderly }{ }^{\mathrm{c}}\end{array}$} & Not applicable & 10 & $(66.7 \%)$ & 11 & $(73.3 \%)$ & .63 \\
\hline & Rank I & 0 & $(0.0 \%)$ & 1 & $(6.7 \%)$ & \\
\hline & Rank II & 4 & $(26.7 \%)$ & 2 & $(13.3 \%)$ & \\
\hline & Rank III & 1 & $(6.7 \%)$ & 1 & $(6.7 \%)$ & \\
\hline Hasegawa dementia rating scale-revised ${ }^{\mathrm{b}}$ & (HDS-R) & $23.3 \pm 5.2$ & (12 to 30$)$ & $22.1 \pm 5.8$ & (11 to 28$)$ & .63 \\
\hline The Geriatric Depression Scale ${ }^{\mathrm{b}}$ & (GDS) & $8.5 \pm 1.8$ & (5 to 12$)$ & $8.7 \pm 3.0$ & (5 to 13$)$ & .52 \\
\hline Zung Self Depression Scale ${ }^{b}$ & (SDS) & $44.5 \pm 7.4$ & (31 to 58$)$ & $45.3 \pm 10.2$ & (29 to 66$)$ & .90 \\
\hline Japan Stroke Scale - Depression Scale & (JSS-D) & $6.2 \pm 3.8$ & (2.4 to 14.1$)$ & $4.4 \pm 1.2$ & (2.6 to 6.9$)$ & .32 \\
\hline $\begin{array}{l}\text { Japan Stroke Scale - } \\
\text { Emotional Disturbance Scale }\end{array}$ & (JSS-E) & $3.38 \pm 4.18$ & $(-0.55$ to 13.95$)$ & $4.0 \pm 3.1$ & $(-0.3$ to 7.78$)$ & .31 \\
\hline Time since stroke(Day) ${ }^{b}$ & & $2224.5 \pm 1534.3$ & (721 to 5990$)$ & $2829.8 \pm 1838.7$ & (441 to 5110 ) & .69 \\
\hline Side of paresisa & Right & 2 & $(13.3 \%)$ & 4 & $(26.7 \%)$ & .65 \\
\hline \multicolumn{7}{|l|}{ Complications (Multiple answers) $^{c}$} \\
\hline & Diabetes mellitus & 2 & $(13.3 \%)$ & 3 & $(20.0 \%)$ & .60 \\
\hline & Hypertension & 7 & $(46.7 \%)$ & 7 & $(46.7 \%)$ & \\
\hline & Osteoarthritis & 1 & $(6.7 \%)$ & 2 & $(13.3 \%)$ & \\
\hline & Fracture & 2 & $(13.3 \%)$ & 5 & $(33.3 \%)$ & \\
\hline & Heart disease & 0 & $(0.0 \%)$ & 2 & $(13.3 \%)$ & \\
\hline & Respiratory disease & 0 & $(0.0 \%)$ & 2 & $(13.3 \%)$ & \\
\hline
\end{tabular}

NOTE. Values are $\mathrm{N}(\%)$, mean $\pm \mathrm{SD}$, or as otherwise indicated.

a Fisher exact test

b Mann-Whitney U test

c Chi-Square Test

Table 2. Differences within groups, differences between groups

\begin{tabular}{|c|c|c|c|c|c|c|c|c|c|c|c|c|c|}
\hline \multirow{3}{*}{\begin{tabular}{|l|} 
Measures \\
Barthel Index \\
\end{tabular}} & \multirow[b]{3}{*}{ (BI) } & \multicolumn{4}{|c|}{ Intervention group $(\mathrm{N}=15)$} & & & \multicolumn{4}{|c|}{ Control group $(\mathrm{N}=15)$} & & \\
\hline & & \multirow{2}{*}{$\begin{array}{c}\text { Pre- } \\
55.3 \pm 20.7\end{array}$} & \multirow{2}{*}{$\begin{array}{c}\text { Post- } \\
58.0 \pm 19.8\end{array}$} & \multicolumn{2}{|c|}{$\begin{array}{l}\text { Differences within } \\
\text { group }(95 \% \mathrm{CI})^{\mathrm{a}}\end{array}$} & \multicolumn{2}{|c|}{$P$ value $^{\mathrm{b}}$} & \multirow{2}{*}{$\begin{array}{c}\text { Pre- } \\
53.0 \pm 20.9 \\
\end{array}$} & \multicolumn{2}{|c|}{ Post- } & \multirow{2}{*}{$\begin{array}{c}\begin{array}{c}\text { Differences } \\
\text { within group } \\
\text { (95\%CI) }^{\mathbf{a}}\end{array} \\
(0.00)\end{array}$} & \multicolumn{2}{|c|}{$P$ value $^{\mathrm{b}}$} \\
\hline & & & & 2.7 & $(-3.24$ to 8.57$)$ & .60 & & & $53.0 \pm 20.9$ & 0.0 & & & \\
\hline Hasegawa dementia rating scale-revised & (HDS-R) & $23.3 \pm 5.2$ & $24.3 \pm 5.8$ & 1.0 & $(-1.30$ to 3.30$)$ & .29 & & $22.1 \pm 5.8$ & $21.5 \pm 5.3$ & -0.6 & $(-1.15$ to 2.35$)$ & .73 & \\
\hline Mini-Mental State Examination & (MMSE) & $23.0 \pm 4.5$ & $24.7 \pm 4.9$ & 1.7 & $(-0.30$ to 3.64$)$ & .11 & & $22.3 \pm 4.8$ & $23.3 \pm 4.0$ & 1.1 & $(-0.43$ to 2.57$)$ & .15 & \\
\hline Frontal Assessment Battery & (FAB) & $9.5 \pm 3.3$ & $12.5 \pm 3.5$ & 2.9 & $(1.28$ to 4.59$)$ & .01 & ${ }^{* *}$ & $9.7 \pm 3.4$ & $10.7 \pm 3.5$ & 1.0 & $(-0.26$ to 2.26$)$ & .09 & \\
\hline The Geriatric Depression Scale & (GDS) & $8.5 \pm 1.8$ & $5.1 \pm 2.5$ & -3.5 & (2.32 to 4.61$)$ & .00 & ${ }^{* *}$ & $8.7 \pm 3.0$ & $8.1 \pm 3.8$ & -0.6 & $(-0.63$ to 1.83$)$ & .33 & \\
\hline Zung Self Depression Scale & (SDS) & $44.5 \pm 7.4$ & $34.1 \pm 7.1$ & -10.3 & (5.46 to 15.21$)$ & .00 & ${ }^{* *}$ & $45.3 \pm 10.2$ & $45.1 \pm 11.9$ & -0.2 & $(-4.15$ to 4.55$)$ & .82 & \\
\hline Japan Stroke Scale - Depression Scale & (JSS-D) & $6.2 \pm 3.8$ & $2.1 \pm 1.3$ & -4.1 & $(2.06$ to 6.14$)$ & .00 & ${ }^{* *}$ & $4.4 \pm 1.2$ & $4.1 \pm 1.6$ & -0.3 & $(-0.29$ to 0.88$)$ & .22 & \\
\hline $\begin{array}{l}\text { Japan Stroke Scale - Emotional } \\
\text { Disturbance Scale }\end{array}$ & (JSS-E) & $3.4 \pm 4.2$ & $1.1 \pm 3.2$ & -1.3 & $(-1.26$ to 4.72$)$ & .16 & & $4.0 \pm 3.1$ & $3.6 \pm 3.1$ & -0.4 & $(-0.54$ to 1.32$)$ & .46 & \\
\hline $\begin{array}{l}\text { Facilities Service Satisfaction Total } \\
\text { score }\end{array}$ & & $39.4 \pm 6.8$ & $42.0 \pm 4.3$ & 2.9 & $(-0.36$ to 6.23$)$ & .06 & & $37.0 \pm 5.6$ & $38.2 \pm 6.9$ & 1.2 & $(0.75$ to 3.15$)$ & .21 & \\
\hline $\begin{array}{l}\text { Rehabilitation Customer Satisfaction } \\
\text { Total score }\end{array}$ & (CSSNS) & $36.2 \pm 4.9$ & $37.6 \pm 6.8$ & 5.5 & $(0.10$ to 10.97$)$ & .07 & & $47.3 \pm 9.3$ & $46.9 \pm 10.4$ & -0.3 & $(-4.57$ to 5.24$)$ & .86 & \\
\hline \multicolumn{14}{|l|}{ SF-8 } \\
\hline Physical functioning & (PF) & $33.5 \pm 17.7$ & $44.5 \pm 14.2$ & 10.9 & $(-2.10$ to 22.65$)$ & .01 & ${ }^{* *}$ & $38.5 \pm 14.1$ & $34.2 \pm 18.6$ & -4.3 & (-6.61 to 15.2$)$ & .41 & \\
\hline Role physical & (RP) & $37.0 \pm 15.6$ & $47.8 \pm 11.7$ & 10.8 & $(-0.99$ to 21.36$)$ & .01 & ${ }^{* *}$ & $42.3 \pm 13.6$ & $37.6 \pm 17.6$ & -4.8 & $(-6.50$ to 16.0$)$ & .39 & \\
\hline Bodily pain & (BP) & $43.9 \pm 13.0$ & $51.5 \pm 9.3$ & 7.6 & $(-5.51$ to 12.56$)$ & .00 & ${ }^{* *}$ & $50.3 \pm 13.8$ & $47.9 \pm 14.4$ & -2.3 & $(-4.37$ to 9.05$)$ & .42 & \\
\hline General health & $(\mathrm{GH})$ & $45.4 \pm 8.7$ & $53.5 \pm 7.9$ & 8.1 & $(-1.02$ to 12.07$)$ & .00 & ${ }^{* *}$ & $47.5 \pm 7.8$ & $47.9 \pm 9.5$ & 0.4 & (3.59 to 4.37 ) & .40 & \\
\hline Vitality & (VT) & $44.3 \pm 9.1$ & $52.7 \pm 8.3$ & 8.4 & $(-3.04$ to 8.21$)$ & .00 & ${ }^{* *}$ & $46.3 \pm 6.6$ & $50.1 \pm 6.7$ & 3.8 & $(-0.63$ to 8.23$)$ & .07 & \\
\hline Social functioning & (SF) & $32.7 \pm 14.7$ & $50.1 \pm 7.7$ & 17.4 & $(-1.76$ to 19.42$)$ & .00 & ${ }^{* *}$ & $43.0 \pm 11.7$ & $39.5 \pm 14.8$ & -3.5 & $(-4.23$ to 11.06$)$ & .37 & \\
\hline Role emotional & (RE) & $50.2 \pm 6.4$ & $51.0 \pm 7.8$ & 0.8 & $(-5.80$ to 5.80$)$ & .50 & & $45.2 \pm 10.0$ & $51.0 \pm 7.8$ & 5.8 & (1.23 to 10.31$)$ & .02 & * \\
\hline Mental health & $(\mathrm{MH})$ & $46.5 \pm 10.5$ & $51.6 \pm 9.2$ & 5.1 & $(-0.21$ to 15.19$)$ & .02 & ${ }^{*}$ & $42.6 \pm 10.7$ & $44.1 \pm 11.3$ & 1.5 & $(-0.74$ to 3.77$)$ & .14 & \\
\hline Physical component summary & (PCS) & $34.9 \pm 14.7$ & $46.6 \pm 9.9$ & 11.7 & $(-1.11$ to 17.72$)$ & .00 & ${ }^{* *}$ & $43.5 \pm 12.8$ & $38.3 \pm 14.8$ & -5.3 & $(-4.25$ to 14.75$)$ & .28 & \\
\hline Mental component summary & (MCS) & $48.2 \pm 8.3$ & $52.3 \pm 8.4$ & 4.1 & $(-2.76$ to 9.20$)$ & .01 & $* *$ & $44.0 \pm 8.5$ & $49.1 \pm 7.5$ & 5.1 & (3.20 to 6.92$)$ & .00 & ** \\
\hline
\end{tabular}

NOTE. Values are $\mathrm{N}$, mean $\pm \mathrm{SD}$, or as otherwise indicated

Abbreviations: CI, confidence intervals

*Significant difference between pre- and post-test values, $P<0.05$, ${ }^{*}$ Significant difference between pre- and post-test values, $P<0.01$

a Wilcoxon signed-rank test, $\mathrm{b}$ Adjusted using the Bonferroni method for multiple testing 
Table3. Differences between groups

\begin{tabular}{|c|c|c|c|c|c|c|}
\hline \multicolumn{2}{|l|}{ Measures } & \multicolumn{2}{|c|}{ Differences between two groups $(95 \% \mathrm{CI})^{\mathrm{a}}$} & \multicolumn{2}{|c|}{ Pvalue ${ }^{b}$} & \multirow{2}{*}{$\begin{array}{c}\text { Effect Size }^{\mathrm{a}} \\
0.623\end{array}$} \\
\hline The Geriatric Depression Scale & (GDS) & 2.9 & $(-0.67$ to 5.47$)$ & .02 & * & \\
\hline Zung Self Depression Scale & (SDS) & 10.1 & (3.68 to 18.32 ) & .01 & *** & 0.686 \\
\hline Japan Stroke Scale - Depression Scale & (JSS-D) & 3.8 & $(0.92$ to 3.11$)$ & .00 & ** & 0.799 \\
\hline $\begin{array}{l}\text { Japan Stroke Scale - Emotional } \\
\text { Disturbance Scale }\end{array}$ & (JSS-E) & 0.9 & $(-0.59$ to 4.64$)$ & .04 & * & 0.532 \\
\hline \multicolumn{7}{|l|}{ SF-8 } \\
\hline Physical functioning & $(\mathrm{PF})$ & -15.3 & $(-2.10$ to 22.65$)$ & .12 & & 0.400 \\
\hline Role physical & (RP) & -15.5 & $(-0.99$ to 21.36$)$ & .09 & & 0.438 \\
\hline Bodily pain & (BP) & -9.9 & $(-5.51$ to 12.56$)$ & .58 & & 0.144 \\
\hline General health & $(\mathrm{GH})$ & -7.7 & $(-1.02$ to 12.07$)$ & .11 & & 0.414 \\
\hline Vitality & (VT) & -4.6 & $(-3.04$ to 8.21$)$ & .24 & & 0.305 \\
\hline Social functioning & $(\mathrm{SF})$ & -20.9 & (-1.76 to19.42) & .04 & * & 0.525 \\
\hline Role emotional & $(\mathrm{RE})$ & 4.9 & $(-5.80$ to 5.80$)$ & 1.00 & & 0 \\
\hline Mental health & $(\mathrm{MH})$ & -3.5 & $(-0.21$ to 15.19$)$ & .07 & & 0.468 \\
\hline Physical component summary & (PCS) & -17.0 & $(-1.11$ to 17.72$)$ & .21 & & 0.321 \\
\hline Mental component summary & (MCS) & 1.0 & $(-2.76$ to 9.20$)$ & .05 & * & 0.514 \\
\hline
\end{tabular}

NOTE. Values are $\mathrm{N}$, mean $\pm \mathrm{SD}$, or as otherwise indicated

Abbreviations: CI, confidence intervaly

*Significant difference between pre and post test values, $\mathrm{P}<0.05$, **Significant difference between pre and post test values, $\mathrm{P}<0.01$

a Mann-Whitney U test, b Adjusted using the Bonferroni method for multiple testing.

\section{Results}

At the pre-training evaluation, no differences in patient characteristics or baseline clinical data were observed between the 2 groups (Table 1). The secondary measures did not differ between the 2 groups. The amount of rehabilitation during the intervention period did not differ between the 2 groups (Table 1 ).

Tables 2 and 3 shows the outcome measures of the 2 groups. The intervention group showed significant increases in FAB $(95 \%$ confidence interval [CI], 1.28-4.59; $P=.01$ ), GDS (95\% CI, 2.32-4.61; $P=.00)$, SDS (95\% CI, 5.46-15.21; $P=.00$ ), JSS-D (95\% CI, $2.06-$ $6.14 ; P=.00)$, Physical component summary (PCS) of SF-8 $(95 \% \mathrm{CI}$, -1.11 - 17.72; $\mathrm{P}=.00)$ and MCS of SF-8 (95\% CI, $-2.76-9.20 ; P=.01)$ whereas in the control group, no difference was observed except for the MCS of SF-8 (95\% CI, 3.20 -6.92; $P=.00$ ). The intervention group showed significantly greater improvement in the GDS (between-group difference $=2.9 ; 95 \% \mathrm{CI},-.67-5.47 ; P=.02$ ), SDS (between-group difference $=10.1 ; 95 \% \mathrm{CI}, 3.68-18.32 ; P=.01$ ), JSS-D (between-group difference $=3.8 ; 95 \% \mathrm{CI}, .92-3.11 ; P=.00$ ), JSS-E (between-group difference $=.90 ; 95 \%$ CI, $-.59-4.64 ; P=.04$ ) and MCS of SF-8 (betweengroup difference $=1.0 ; 95 \% \mathrm{CI},-2.76-9.20 ; P=.05)$ than did the control group.

\section{Discussion}

To the best of our knowledge, this is the first randomized trial to show the efficacy of cognitive rehabilitation to improve the depressive symptoms and cognitive function for PSD patients. Pre-training evaluation revealed that the participants in our study were depressed and had declined frontal lobe function. Post-training evaluation demonstrated that for participants in the intervention group both their depressive symptoms and frontal lobe function were improved after completing the cognitive rehabilitation intervention. The results obtained in this trial indicate that depressive symptoms and frontal lobe function can be improved by the addition of cognitive rehabilitation to the usual exercise-based rehabilitation programs.

Van Eeden and colleagues [43] reported an economic evaluation of cognitive behavioral therapy (CBT) intervention versus computerized cognitive training for PSD symptoms. Both interventions consisted of
13-16 sessions over a period of 4 months. The computerized cognitive training was an individual, patient-tailored computerized cognitive training program in which patients executed computer tasks on their own cognitive level. As a result of the intervention, they reported that both treatments showed a therapeutic effect on PSD symptoms. Based on their report, cognitive rehabilitation was considered effective for patients with PSD, however, we could not find other studies that reported the effects of cognitive rehabilitation on patients with PSD symptoms.

In Japan, cognitive rehabilitation is generally provided by occupational therapists or clinical psychologists. In this study, the cognitive rehabilitation program consisted of common attentionrelated work tasks rather than computer-based exercises and it was shown to be effective in improving depressive symptoms.

Sou and colleagues [44] reported that computerized cognitive training $(\mathrm{CCT})$ attenuated decline in memory performance in patients with mild cognitive impairment, and showed, using function MRI, that the effect was mediated by enhanced functional connectivity between the hippocampus and superior frontal cortex. Brain changes of patients with major depression were characterized by diffuse bilateral grey matter loss in the ventrolateral and ventromedial frontal systems extending into the temporal gyri and hippocamp compared to healthy controls [45]. Considering these findings, it seems reasonable to suggest that cognitive rehabilitation acts upon the areas of the brain related to depression and thereby ameliorates depressive symptoms.

In this study, the control group performed a typical rehabilitation, which consisted of exercise therapy. Recently, favorable effects of exercise therapy on depression have been reported [26]. One study reported that resistance training exercise leads to improvement of cognitive function in patients with mild cognitive impairment [46]. The exercise therapy performed in our control group was of a low intensity. While there was a positive effect on QOL, it was not effective for improving depression or cognitive function. Underwood and colleagues ${ }^{22}$ reported that at aged 65 years or older, a moderately intense exercise program did not reduce depressive symptoms in residents of care homes. It seems that the effect of exercise therapy for elderly patients with depression might be different from its effect on depression in general. 
In our study, the QOL of patients with PSD was improved as a result of cognitive rehabilitation. Cumming and colleagues [47] showed that cognitive impairment and poorer attention were associated with lower QOL among post-stroke patients after 3 and 12 months after onset. In addition, Cao and colleagues [48] showed that there was a negative correlation between QOL and depression among elderly people. Therefore, in addition to its benefit for ameliorating depression, cognitive rehabilitation may also be effective for improving the QOL of patients with PSD.

Apathy has been reported as one of the primary clinical features among post-stroke patients. Starkstein and colleagues [49] reported that major depression was associated with an increased frequency of apathy and that apathy was also significantly associated with older age, cognitive impairment, and impairment of ADL. Okada and colleagues [50] estimated the severity of apathy using an Apathy Scale and regional cerebral blood flow in stroke patient and demonstrated that apathy may be accompanied by cognitive impairments, depressive state, and frontal dysfunction. Further, they reported the hypoactivity in the frontal lobe and anterior temporal regions. In our study, results of the pre-training evaluation showed that the patients with PSD were also apathetic. However, post-training evaluation demonstrated that this apathetic condition improved significantly in the intervention group compared to the control group. Based on these findings, cognitive rehabilitation seems to be effective for reducing apathetic symptoms by promoting frontal lobe function.

This study has some limitations. Questions remain about the optimal duration of rehabilitation, the best duration for a training session, intervention frequency, exercise load, and long-term effects of cognitive rehabilitation and low-intensity exercise. We will attempt to answer these questions in future investigations.

\section{Clinical messages}

The results obtained in this randomized controlled trial suggest that the inclusion of cognitive rehabilitation to the usual low-intensity exercise therapy rehabilitation program could improve depressive symptoms in patients with PSD more efficiently than exercise rehabilitation alone. Further randomized controlled studies on a larger scale are needed to clarify its effectiveness.

\section{Acknowledgment}

We thank Thomas Mayers of the Medical English Communications Center, University of Tsukuba, for editing and revision of this manuscript.

\section{Conflict of interest}

The authors have no conflict of interest to declare.

\section{Funding}

This research received no specific grant from any funding agency in the public, commercial, or not-for-profit sectors.

\section{References}

1. Rasquin SM, Van De Sande P, Praamstra AJ (2009) Cognitive-behavioural intervention for depression after stroke: five single case studies on effects and feasibility. Neuropsychol Rehabil 19: 208-222. [Crossref]

2. Aben I, Verhey F, Strik J (2003) A comparative study into the 1 year cumulative incidence of depression after stroke and myocardial infarction. J Neurol Neurosurg Psychiatry 74: 581-585. [Crossref]

3. De Wit L, Putman K, Baert I (2008) Anxiety and depression in the first 6 months after stroke. A longitudinal multicenter study. Disabil Rehabil 30: 1858-1866. [Crossref]
4. Gainotti G, Azzoni A, Lanzillotta M (1995) Some preliminary findings concerning a new scale for the assessment of depression and related symptoms in stroke patients. Ital J Neurol Sci 16: 439-451. [Crossref]

5. van Mierlo ML, van Heugten CM, Post MWM (2014) A longitudinal cohort study on quality of life in stroke patients and their partners: Restore4Stroke Cohort. Int J Stroke 9: 148-154. [Crossref]

6. Wilkinson PR, Wolfe CD, Warburton FG, Rudd AG, Howard RS, et al. (1997) A longterm follow-up of stroke patients. Stroke 28: 507-512. [Crossref]

7. Maiko O, Kaori M, Meigen L (2007) Poststroke Depression: Diagnosis and Treatment Jpn J Rehabil Med 44: 177-188.

8. Gall A (2001) Post stroke depression. Hosp Med 62: 268-273. [Crossref]

9. Kimura M (2012) Depression and apathy following stroke. J Jpn Cong Neuro Emrgs 24:71-77.

10. Kijowski S (2014) Difficulties in post-stroke gait improvement caused by post-stroke depression. Chin Med J (Engl) 127: 2085-2090. [Crossref]

11. Volz M, Möbus J, Letsch C, Werheid K (2016) The influence of early depressive symptoms, social support and decreasing self-efficacy on depression 6 months poststroke. J Affect Disord 206: 252-255. [Crossref]

12. Shimoda K, Robinson RG (1999) The relationship between poststroke depression and lesion location in long-term follow-up. Biol Psychiatry 45: 187-192. [Crossref]

13. Sakamoto H, Takata Y, Inada H (2014) Factors related to customer satisfaction with rehabilitation in geriatric facilities. An official journal of the Japan Primary Care Association 37: 324-32

14. Bhogal SK, Teasell R, Foley N (2004) Lesion location and post stroke depression systematic review of the methodological limitations in the literature. Stroke 35: 794 802. [Crossref]

15. Carson AJ, MacHale S, Allen K, Lawrie SM, Dennis M, et al. (2000) Depression after stroke and lesion location: a systematic review. Lancet 356: 122-126. [Crossref]

16. Robinson RG (2003) Poststroke depression: prevalence, diagnosis, treatment, and disease progression. Biol Psychiatry 2003; 54: 376-387. [Crossref]

17. Shi YZ, Xiang YT, Yang Y (2016) Depression after minor stroke: the association with disability and quality of life--a 1-year follow-up study. Int J Geriatr Psychiatry 31: 421-427. [Crossref]

18. Hackett ML, Anderson CS (2005) Predictors of depression after stroke: a systematic review of observational studies. Stroke 36: 2296-2301. [Crossref]

19. Hackett ML, Anderson CS, House A (2008) Interventions for preventing depression after stroke. Cochrane Database Syst Rev 3: CD003689. [Crossref]

20. Palomäki H, Kaste M, Berg A (1999) Prebention of post stroke depression: 1year randomized placebo controlled double blind trial of mianserin with 6 month up after therap. J Neurol Neurosurg Psychiatry 66: 490-494. [Crossref]

21. Carek PJ, Laibstain SE, Carek SM (2011) Exercise for the treatment of depression and anxiety. Int J Psychiatry Med 41: 15-28. [Crossref]

22. Underwood M, Lamb SE, Eldridge S (2013) Exercise for depression in elderly residents of care homes:a cluster-randomised controlled trial. Lancet 382: 441-449

23. Schuch FB, Vancampfort D, Richards J, Rosenbaum S, Ward PB, et al. (2016) Exercise as a treatment for depression: A meta-analysis adjusting for publication bias. J Psychiat Res 77: 42-51. [Crossref]

24. Huntley JD, Gould RL, Liu K (2015) Do cognitive interventions improve general cognition in dementia? A meta-analysis and meta-regression. BMJ Open 5: 1-12. [Crossref]

25. Cho HY, Kim KT, Jung JH (2015) Effects of computer assisted cognitive rehabilitation on brain wave, memory and attention of stroke patients: a randomized control trial. $J$ Phys Ther Sci 27: 1029-1032. [Crossref]

26. Sakamoto H, Maki N, Ustugi A (2017) The effects of cognitive rehabilitation on patients with post-stroke depression in long-term care facilities: a before-and-after comparison trial. An official journal of the Japan Primary Care Association.

27. Robinson RG (2013) The Clinical Neuropsychiatry of Stroke: Cognitive, behavioral, and emotional disorders following vascular brain injury Second Edition. Seiwa Shoten 43-45.

28. Yesavage JA, Brink TL, Rose TL, Lum O, Huang V, et al. (1982) Development and validation of a geriatric depression screening scale: a preliminary report. $J$ Psychiatr Res 17: 37-49. [Crossref] 
29. Yoshiaki K, Koichi H (2008) Usefulness of the Japan Stroke Scale, Depression Scale (JSS-D) for the Diagnosis of Post-stroke Depression. Intern Med 47: 225-229. [Crossref]

30. Kato S, Shimogaki H, Onodera A (1991) Creating a Hasegawa Dementia rating ScaleRevised (HDS-R). Japanese journal of geriatric psychiatry 2: 1339-1347.

31. Faul F, Erdfelder E, Lang AG, Buchner A (2007) G*Power 3: A flexible statistical power analysis program for the social, behavioral, and biomedical sciences. Behav Res Methods 39: 175-191. [Crossref]

32. Sawilowsky SS (2009) New effect size rules of thumb. Journal of Modern Applied Statistical Methods 8: 597-599.

33. Scarpina F, Tagini S (2017) The Stroop Color and Word Test. Front Psychol 8: 557. [Crossref]

34. Inoue M, Suyama A, Kato T (2003) Development of computerized Kana Pick-out Test for the neuropsychological examination. Comput Methods Programs Biomed 70: 271276. [Crossref]

35. Zung WW (1965) A self-rating depression scale. Arch Gen Psychiatry 12: 63-70. [Crossref]

36. Japan Stroke Scale (2003) The Stroke Scale Committee of the Japan Stroke Society Emotional Disturbance Scale Committee. The Japan Stroke Society 25: 206-214.

37. Folstein MF, Folstein SE, McHugh PR (1975) Mini-mental state: A practical method for grading the cognitive state of patients for the clinician. J Psychiat Res 12: 189-198. [Crossref]

38. Dubois B, Slachevsky A, Litvan I, Pillon B (2000) The FAB: a Frontal Assessment Battery at bedside. Neurology 55: 1621-1626. [Crossref]

39. Kennedy KJ (1981) Age effects on Trail Making Test performance. Percept Mot Skills 52: 671-675. [Crossref]
40. Mahoney FI, Barthel DW (1965) Functional Evaluation: the Barthel Index. Md State Med J 14: 61-65. [Crossref]

41. Tanaka R, Tokaji A (2010) Examination of the Cross-Validity of Customer Satisfaction Scale Based on Need Satisfaction: A Survey of Rehabilitation Services. Rigakuryoho Kagaku 25: 95-101.

42. SF (2014) The SF community Offering information and discussion on health outcomes. Available at: URL: http://www.sf-36.org/.

43. van Eeden M, Kootker JA, Evers SM (2015) An economic evaluation of an augmented cognitive behavioural intervention vs. computerized cognitive training for post-stroke depressive symptoms. BMC Neurol 15: 266. [Crossref]

44. Suo C, Singh MF, Gates N (2016) Therapeutically relevant structural and functiona mechanisms triggered by physical and cognitive exercise: Mol Psychiatry 21:1633-42. [Crossref]

45. Arnone D, Job D, Selvaraj S (2016) Computational meta-analysis of statistical parametric maps in major depression. Hum Brain Mapp 37:1393-1404.

46. Fiatarone Singh MA, Gates N, Saigal N (2014) The Study of Mental and Resistance Training (SMART) Study-resistance Training and/or Cognitive Training in Mild Cognitive Impairment: A Randomized, double-blind, double-sham controlled trial. J Am Med Dir Assoc 15:873-80. [Crossref]

47. Cumming TB, Brodtmann A, Darby D, Bernhardt J (2014) The importance of cognition to quality of life after stroke. J Psychosom Res 77: 374-379. [Crossref]

48. Cao W, Guo C, Ping W, Tan Z, Guo Y, et al. (2016) A Community-Based Study of Quality of Life and Depression among Older Adults. Int J Environ Res Public Health 13. [Crossref]

49. Starkstein SE, Fedoroff JP, Price TR, Leiguarda R, Robinson RG (1993) Apathy following cerebrovascular lesions. Stroke 24: 1625-1630. [Crossref]

50. Okada K, Kobayashi S, Yamagata S, Takahashi K, Yamaguchi S (1997) Poststroke apathy and regional cerebral blood flow. Stroke 28: 2437-2441. [Crossref]

Copyright: $\odot 2018$ Sakamoto H. This is an open-access article distributed under the terms of the Creative Commons Attribution License, which permits unrestricted use, distribution, and reproduction in any medium, provided the original author and source are credited. 